\title{
Risk assessment of pesticides in estuaries: a review addressing the persistence of an old problem in complex environments
}

\author{
Nagore Cuevas $\mathbb{D}^{1} \cdot$ Marta Martins $\mathbb{D}^{2,3} \cdot$ Pedro M. Costa $\mathbb{D}^{1}$
}

Accepted: 5 February 2018

(c) Springer Science+Business Media, LLC, part of Springer Nature 2018

\begin{abstract}
Estuaries, coastal lagoons and other transition ecosystems tend to become the ultimate reservoirs of pollutants transported by continental runoff, among which pesticides constitute the class of most concern. High amounts of dissolved and particulated organic matter greatly contribute to the accumulation of pesticides that eventually become trapped in sediments or find their way along food chains. Perhaps not so surprisingly, it is common to find elevated levels of pesticides in estuarine sediments decades after their embargo. Still, it remains challenging to address ecotoxicity in circumstances that invariably imply mixtures of contaminants and multiple factors affecting bioavailability. Despite advances in methods for detecting pesticides in waters, sediments and organisms, chemical data alone are insufficient to predict risk. Many researchers have been opting for ex situ bioassays that mimic the concentrations of pesticides in estuarine waters and sediments using a range of ecologically relevant model organisms, with emphasis on fish, molluscs and crustaceans. These experimental procedures unravelled novel risk factors and important insights on toxicological mechanisms, albeit with some prejudice of ecological relevance. On the other hand, in situ bioassays, translocation experiments and passive biomonitoring strive to spot causality through an intricate mesh of confounding factors and cocktails of pollutants. Seemingly, the most informative works are integrative approaches that combine different assessment strategies, multiple endpoints and advanced computational and geographical models to determine risk. State-of-art System Biology approaches combining high-content screening approaches involving "omics" and bioinformatics, can assist discovering and predicting novel Adverse Outcome Pathways that better reflect the cumulative risk of persisting and emerging pesticides among the wide range of stressors that affect estuaries.
\end{abstract}

Keywords Transition ecosystems $\cdot$ Brackish water $\cdot$ Sediments $\cdot$ Toxicity $\cdot$ Contaminant mixtures $\cdot$ Systems biology

Pedro M. Costa

pmcosta@fct.unl.pt

Nagore Cuevas

n.cuevas@fct.unl.pt

Marta Martins

marta.martins@fct.unl.pt

1 UCIBIO - Research Unit on Applied Molecular Biosciences, Departamento de Ciências da Vida, Faculdade de Ciências e Tecnologia da Universidade Nova de Lisboa, 2829-516 Caparica, Portugal

2 MARE - Marine and Environmental Sciences Centre, Departamento de Ciências e Engenharia do Ambiente, Faculdade de Ciências e Tecnologia da Universidade Nova de Lisboa, 2829516 Caparica, Portugal

3 UCIBIO, REQUIMTE, Departamento de Química, Faculdade de Ciências e Tecnologia, Universidade Nova de Lisboa, 2829-516 Caparica, Portugal

\section{Introduction}

The best-selling book Silent Spring (Carson 1962) revealed the persistence and impact of the first modern-day pesticide onto the environment, the insecticide DDT (dichloro diphenyl trichloroethane), caused by its indiscriminate use. The long battle that led to worldwide restraints on the use of DDT paved the way to the continuous cycle of development-and-ban of novel pesticides. Not surprisingly, pesticides, a term that encompasses chemicals employed mostly as herbicides, insecticides and fungicides for agricultural applications, tend to be transported to freshwater bodies via runoff and aerial deposition from agricultural plots (refer for instance to the comprehensive work on pesticide use by Matthews 2015). From here, they join the broad rank of pollutants that tend to accumulate in estuaries and other transition ecosystems. However, the persistence of old and new pesticides in estuarine waters, sediments and 
biota, plus their effects, remains little surveyed comparatively to freshwater systems. This gap results from a few major constraints that hinder establishing the cause-effect relationships that are needed to assess risk: (i) estuaries are dynamic and intrinsically complex ecosystems and (ii) they are the final recipients of the vast majority of contaminants from anthropogenic and natural origins, point or diffuse. This latter aspect implies, in the very particular case of pesticides, addressing the existence and consequences of substances that are directed against specific biological targets amidst a cocktail of hazardous chemicals. The current review will briefly explore the particularities and challenges of monitoring pesticides in estuaries in face of the growing awareness that pollution is more than the sum of its parts and that there are novel tools being incorporated into aquatic ecotoxicology to address the old but subsisting problem of pesticide contamination.

Besides their persistence in the environment, the concerns about pesticides are related to their potential to cause adverse effects in non-target organisms and their ability to bioaccumulate, in large part owing to their lipophilicity (Schäfer et al. 2007). The effects of pesticides, even at residual concentrations, can range between endocrine disruption, damage to nervous system and immunotoxicity to the inhibition of photosynthesis (Casida 2009; Poletta et al. 2009). These effects are not restricted to wild organisms, as there is evidence from experimental and epidemiological data that pesticides pose a very significant threat to humans as well, which reiterates the importance of monitoring affected areas (see Mrema et al. 2013 for a review). Furthermore, pesticide metabolites (derived from physically, chemically or biologically degraded parent compounds) can be even more hazardous than the pristine substances (Gwiazda et al. 2015; Routti et al. 2009). The environmental hazards resulting from pesticide use are linked to the purpose for which they have been designed: (i) combat agricultural pests, (ii) control the vectors for human diseases and (iii) counter-act organisms that may damage human structures (Cooper and Dobson 2007).

Despite the benefits of pesticides, which a number of human activities rely on, the excessive use of these compounds, mainly in extensive agriculture, leads to growing contamination of estuarine areas via different inputs, such as surface runoff, leakage, spray drifts and accidental spills from chemical industry (Reichenberger et al. 2007; Meffe and Bustamante 2014; Elibariki et al. 2017). Seasonality is, inclusively, a major factor that affects pesticide transport to and along freshwater streams (increased during heavier rainfall), and consequently to estuaries, which has important implications for monitoring procedures (Lefrancq et al. 2017). Depending on the properties of compounds and also of soils (such as their potential for erosion), pesticides can be transported to the aquatic environments dissolved in water, bound to suspended matter and adsorbed to soil particles, in any case tending towards deposition in aquatic sediments, especially those of transition ecosystems, where salt-freshwater confluence favours precipitation (Cooper et al. 2003; Bereswill et al. 2012). Also, the peculiar geochemical characteristics of these transition ecosystems, which favour the formation and sedimentation of particulate organic matter, make estuaries ideal traps for pollutants. Emphasis is given to the more lipophilic substances, as these become easily adsorbed to organic particulates and fine sediments. The reader is diverted to the recent works by Smalling et al. (2013a) and Lorenz et al. (2016) on pesticide partioning in aquatic habitats adjacent to agricultural areas. Consequently, residence times of pesticides in estuaries can be exceptionally prolonged. Even long-banned organochlorine pesticides like DDT are still being found in sediment layers of estuaries, contributing to chronic toxicological effects to organisms collected from areas adjacent to freshwater inputs (see Carvalho et al. 2009; Smalling et al. 2013b; Anderson et al. 2014; Costa et al. 2014). Despite its hazards, the lack-of suitable alternatives is responsible at least for (re)considering the use this pesticide as an affordable way to control vectors of disease in many developing countries (van den Berg 2009), which raises future concerns for the environment. It must be noted that, even following bans, pesticides and their hazardous by-products may become bioavailable, either through slow release from sediments or if the geophysical milieu episodically favours bioavailability (e.g., through oxic-anoxic shifts resulting from disturbance). They can then be bioaccumulated, biomagnified along food chains and cause negative effects to susceptible species (for instance Smalling et al. 2013b).

In the European Union (EU), as for most industrialised nations, there are environmental quality standards (EQS) or similar guidelines that set the maximum admissible thresholds for pollutants in the environment, with emphasis on surface waters. These guidelines set the regulatory admissible limits for a range of substances, among which pesticides represent a major fraction. In the EU the EQS Directive (2008/105/EC and subsequent amendments) has direct implications for the Water and Marine Strategy Framework Directives (2013/39/EU and 2008/56/EC, respectively), which aim at safeguarding the quality of aquatic environments. The strategy evidently implies the monitoring of ecosystems to ascertain the concentrations of pollutants in the environment and determine whether they reach the threshold of effects to biota. The "dirty dozen" pesticides, a group that includes those banned from most developed countries, allocates compounds, such as DDT, hexachlorobenzene, toxaphene, aldrin and dieldrin, all of which are highly toxic to biota and humans. They are, inclusively, regarded as persistent organic pollutants (POPs) 
and are regulated by the Stockholm Convention of the United Nations Environment Programme, which ultimately aims at replacing these and other pesticides (19, at the present) by more ecologically sustainable alternatives. Nonetheless, EQSs and similar guidelines for these pollutants have essentially been derived for individual substances, which creates further challenges for ecotoxicologists in a day and age when novel engineered pesticides are made available practically on an annual basis.

Altogether, the challenges of monitoring pesticides in estuaries result from three major factors: (i) the natural biological and physico-chemical complexity of transition ecosystems; (ii) multiple sources of pollutants, both point and diffuse and (iii) the fact that pesticides are a just one of the components in intricate cocktail of chemicals that continuously join the ranks of estuarine pollutants. As these factors hinder establishing conclusive cause-effect relationships, researchers in the field now acknowledge that monitoring pesticides in estuaries must be an integrative procedure that begins with laboratory testing of new chemicals and their metabolites and proceeds to a range of chemical and biological analyses in situ. We will briefly provide an overview of the current methodologies that are available to address the pesticide problem in estuaries and highlight some of the most significant research examples that provide guidance to the next-generation of toxicologists and ecotoxicologists.

\section{Challenges in environmental risk assessment}

Enhanced by the vast range of old and novel compounds with varying temporal and spatial scale of use, pesticides are usually present in estuaries as complex mixtures. This means that the combined action of co-occurring pesticides can result in additive or synergistic interactions whose outcomes are higher levels of toxicity than predicted. In fact, there are multiple studies demonstrating that complex pesticide mixtures in aquatic environments generate a combined effect that exceeds that of each individual compound (Juhel et al. 2017; Cedergreen 2014). It must also be noted that monitoring strategies which encompass reduced or sporadic sampling largely underestimate pesticide concentrations and fluxes (Assoumani et al. 2013; Bieroza and Heathwite 2015) and fail to assess acute pesticide exposure (Lorenz et al. 2016). In labile, high-seasonality ecosystems like estuaries, this problem must not be neglected. As such, great effort has been made to develop more robust monitoring strategies that, hopefully, should contribute to stricter regulatory strategies. Still, important questions are still pending. Are we monitoring and regulating the most hazardous pesticides? Are we considering new emerging pesticides? Are we evaluating episodic events (e.g., droughts, floods, remobilisation of sediments) in monitoring strategies? Is the predicted toxicity for single compounds realistic in presence of other toxicants, pesticides or not?

In face of these questions, there is a growing effort uphold integrative strategies for the purpose of environmental risk assessment (ERA) in transition ecosystems. Traditionally, these include chemical analyses of diverse matrices (i.e., water, sediment and biota) plus a number of approaches to identify and quantify exposure and potential adverse effects onto estuarine organisms or their convenient proxies. The multiple endpoints offer more robust causeeffect relationships than, for instance, surveying biological effects or concentrations of pollutants alone (see Chapman et al. 2013). In general, the outline of such strategies ranges from studies involving testing of natural waters ex situ onto surrogate crustaceans, such as Daphnia (Cruzeiro et al. 2017) to multi-endpoint Best Professional Judgement approaches to address complex scenarios implicating a wide range of mixed pollutants, multiple estuarine species, in vitro testing and even epidemiology (Caeiro et al. 2017). In Table 1, we highlight some of the most representative works that aimed at ERA in estuaries that are either focused on pesticides specifically or include pesticides among a large array of pollutants. The integration of multiple endpoints, not only across various levels of biological organisation (e.g., molecular to individual), but also comprehensive data on environmental chemistry and even different strategies of bioassays, has proven its worth to disclose the relevance of pesticides amidst highly complex pollutant mixtures in estuaries (Costa et al. 2012a). Other approaches even include the design of biogeographical models based on multiple endpoints. It is the case of the work by Costa et al. (2014), who pinpointed the areas most likely affected by pesticides in an estuary subjected to diffuse contamination by integrating the distribution of main toxicants (including organochlorine pesticides), the effects onto local aquatic species and in vitro testing of sediment extracts with human cell lines. However, the few integrative works dealing with estuaries and pesticides also showed how challenging establishing causation really is and the need to employ adequate computational strategies.

Quite oppositely, most studies that aimed at assessing the risk of pesticides in estuaries purely predicted toxicity from environmental concentrations of compounds of interest. For instance, ecological and human health risk assessments were evaluated from a theoretical perspective by Cruzeiro et al. (2016a), using a multi-matrix quantification of pesticides for the Tagus River estuary (W Portugal). The concentrations of pesticides in the dissolved aqueous phase (DAP), suspended particulate matter (SPM) and in the clam Scrobicularia plana soft tissues were then integrated to calculate risk quotients. The same authors were able to disclose a potential measure of risk for aquatic organisms, mainly invertebrates, however lacking effective validation. 


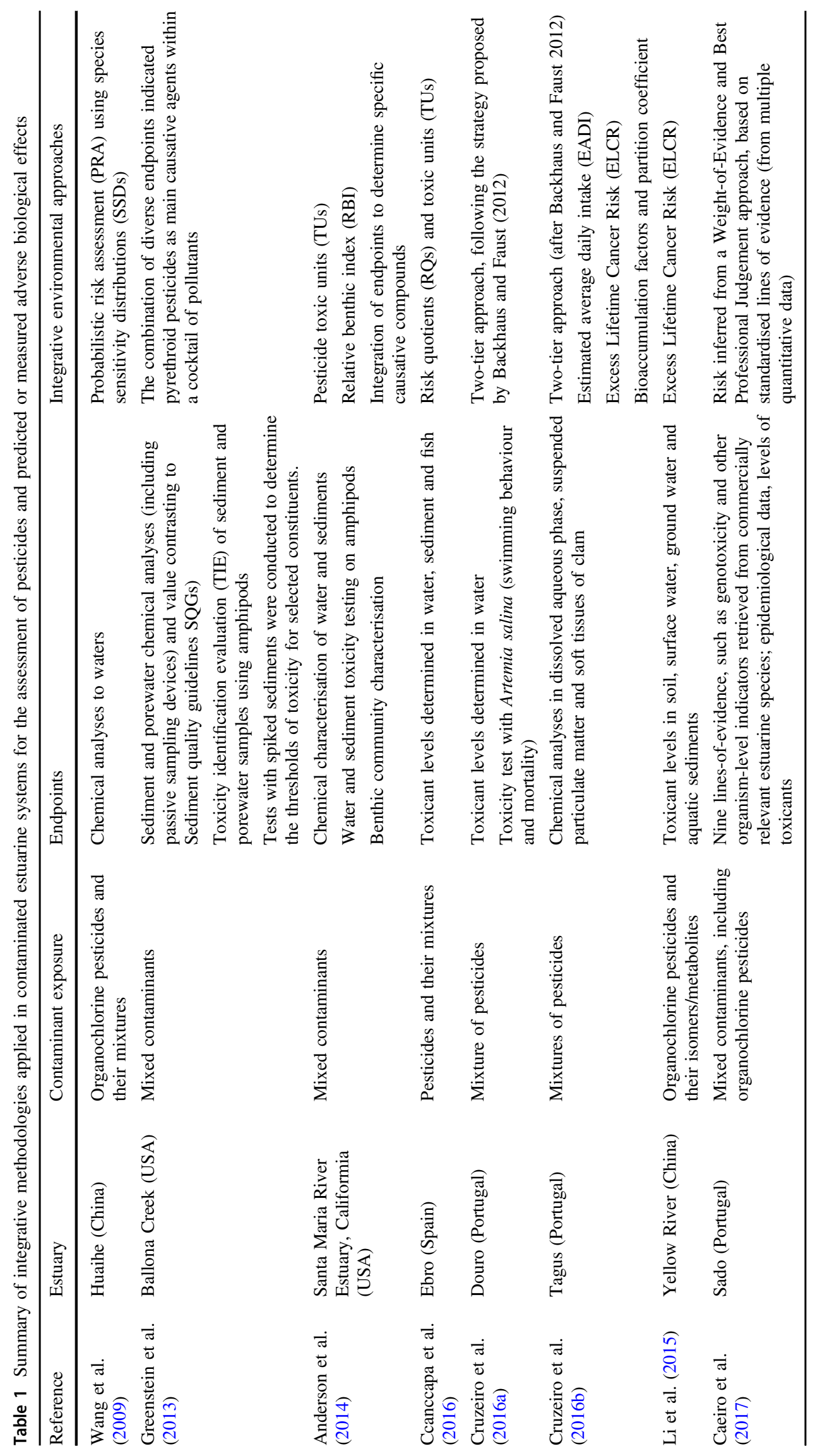


Another recent study, which considered Sediment Quality Guidelines (SQGs) as thresholds to predict toxicity, yielded the potential to occur "rare" to "occasional" biological adverse effects on aquatic biota resulting from the levels of organochlorine pesticides (OCP) found in the Tiber River and Estuary, in Italy (Montuori et al. 2016).

The need to develop integrative approaches to assess contamination by pesticides and other pollutants in coastal areas has been regarded as pivotal for regulatory purposes in the EU (Borja et al. 2010). For that purpose, there are several in situ methodologies currently under trial, such as weight-of-evidence (WOE), effects-directed analysis (EDA), toxicity identification evaluation (TIE), to quote major examples. In order to determine the causative factors of complex environmental pollution, EDA approaches employ in vitro assays to detect organic chemical mixtures in the estuarine environment and their measurable toxic effects, being said to have a remarkable specificity for pollutant identification and determination Scheurell et al. (2007), albeit reduced ecological realism. Conversely, TIE is characterised by the absence of pollutant specificity but increased realism, since this approach is based on wholeorganism methods, and is acknowledged to more adequately reflect bioavailability of pollutants (USEPA 2007). The weight-of-evidence (WOE) approach has been chiefly applied to address sediment contamination in transition ecosystems and integrates biological and chemical data recorded through a multidisciplinary approach composed of different lines of evidence (LOEs). The LOEs of this challenging approach in terms of data interpretation typically include toxicant determination in the environment, toxicity biomarkers and indicators of exposure (Costa et al. 2012a; Martins et al. 2012).

\section{Methods to determine pesticide ecotoxicity in transition ecosystems}

In view of the abovementioned difficulties for evaluating the potential toxicity of mixtures involving pesticides in complex ecosystems, many methods have been developed for estuarine and other coastal environments (Allan et al. 2006). The first step is usually the determination of pesticide levels, which benefits from recent technical improvements. These can be applied not only on waters and sediments, but also on biological samples to determine bioaccumulation and biomagnification (Allan et al. 2006). Methods involving gas chromatography (GC) or highperformance liquid chromatography (HPLC) coupled to mass spectrometry (MS) or tandem mass spectrometry (MS/ MS) are the most traditional approaches to determine pesticides and their by-products, depending on their polarity, volatility and degradability at high temperatures (Cruzeiro et al. 2016b; Domínguez et al. 2016), similarly to other organic and lipophilic pollutants (see also Muir and Sverko 2006; Ferreira et al. 2003). Preparatory extraction and/or pre-concentration steps are usually required, typically using liquid-liquid extraction/microextraction (LLE/LLME) (Chorney et al. 2017), solid phase extraction/microextraction (SPE/SPME) (Lord and Pawliszyn 2000) and singledrop microextraction (SDME) (Cortada et al. 2009). However, unlike for metals, these methods are laborious and require specific adaptations at least for different classes of pesticides.

Passive sampler devices, which are capable of accumulating contaminants dissolved in water, have recently been regarded as a promising alternative within passive monitoring techniques for quantifying pesticides in situ (Vrana et al. 2005). Nevertheless, passive samplers have also been applied in laboratory assays (Pesce et al. 2011; Kim Tiam et al. 2016). The deployment of passive samplers my overcome some artefacts (e.g., presence of colloids and small particles) and permit a time-integrated assessment in water, showing time-weighted average levels of pesticides, even at low concentrations (Allan et al. 2006). However, they continue to be time-consuming and organic solventintensive, which increases costs and hazards (Perron et al. 2013). Several types of passive sampling devices have recently been developed for pesticides assessment, such as Solid Phase Microextraction (SPME) and Chemcatcher. Thus, the passive samplers should be selected according to the aim of the study, since these devices are dependent on the compounds and the specific environmental factors of study area, such as, for instance, water temperature (Ahrens et al. 2015).

A common strategy is to compare the levels of pesticides in environmental samples with available guidelines like the EU EQS mentioned above, to infer risk. Nonetheless, the specific environmental conditions of sampling sites (e.g., suspended solid particles, dissolved oxygen, $\mathrm{pH}$, conductivity, salinity, and temperature) may modify contaminant bioavailability, chemistry and subsequent toxicity, especially in such variable environments like estuaries. Similarly, the concentrations of pesticides in transition ecosystems, particularly in waters, are normally undetectable unless pre-concentration treatments are done (Hanke et al. 2012). Altogether, caution is mandatory when inferring risk from toxicant levels alone. In fact, unless concentrations of pesticides in the environment attain very high or very low levels, validating biological effects is paramount. Without prejudice, toxicity data are always turned more robust if complemented with environmental chemistry.

Addressing toxicity implies either collecting specimens from the wild or subjecting relevant proxies to the toxicants of interest and surveying several endpoints that indicate exposure, response or effect, which calls for the traditional 
"biomarker" approach. By simpler terms, biological analyses may provide a more direct indication of "pollution" (see Allan et al. 2006; Lehtonen et al. 2014). However, one of the major problems is the general lack-of-specificity of biomarkers towards pollutants, particularly when complex mixtures are involved. This problem is recurrent even when dealing with pesticides, which are "designed" to target more or less-specific organisms but often exert deleterious effects onto others. Less-specific biomarkers, like histopathological traits or genotoxicity indicators, may provide a broad overview of adverse effects caused by mixtures, but their association with a given toxicant can be perilous. Even today there are virtually no true "specific" biomarkers for pesticides. Actually, some of the most significant works in the field have accomplished the opposite, i.e., exclude a range of effects, such as the case of the herbicide glyphosate over genotoxic events in animals (e.g., Brusick et al. 2016). The discussion about biomarkers use and choice, due to its very generalist character, is outside the scope of the current work. To that purpose, the reader is diverted to the excellent works by van der Oost et al. (2003) and Chapman et al. (2013). The other problem relates to confounding ("noise") variables that can compromise assessment. Evidently, that are more internal (biological) and external (environmental) confounding factors in pure in situ surveys than in ex situ (laboratory) testing. In general, ecotoxicologists are faced with the decision between enforcing "ecological realism" or reducing the effect of confounding factors (see for instance Martins and Costa 2015). The decision must be carefully balanced and usually involves the choice of sampling and bioassay method, as well as target species. Likely on the account of the many difficulties of ascertaining cause-effect associations, the number of studies addressing pesticides and adverse effects to estuarine biota is surprisingly low.

The strategy that offers more ecological realism is passive biomonitoring. It implies collecting organisms from the wild (such as crabs, bivalves and flatfish) and is the basis for the oldest biomonitoring programmes worldwide. For instance, the Mussel Watch programme has been operating in the US since the mid-1970s (Goldberg 1975). Passive biomonitoring has the great advantage of reflecting longterm effects of exposure (Regoli et al. 2006). However, it is highly affected by confounding factors, from age and reproductive status (and therefore season) to environmental parameters like temperature, salinity or food availability. The election of sentinel species should not, of course, be trivial (see Besse et al. 2012). In order to better segregate between anthropogenic and natural causes of biological effects, many authors reasonably argued that establishing baseline levels for different biological endpoints is crucial, inclusively to track down the potential effects of pesticides in coastal environments (Brenner et al. 2014; Cuevas et al. 2015; Izagirre et al. 2008). In addition, the selection of adequate reference sites is complicated but paramount to isolate pollutant induced-effects (see Hering et al. 2010). Despite the difficulties in establishing cause-effect relationships between pesticides and adverse effects in estuarine organisms using passive biomonitoring, there have been cases that have linked patterns of effects (from histopathology to oxidative stress) to the persistence of organochlorine pesticides even amidst a wide range of pollutants (e.g. Ricciardi et al. 2010; Rodrigo et al. 2013; Costa et al. 2013, 2014)

Ex situ bioassays, on the other hand, can restrain confounding variables, albeit at loss-of-ecological realism. They can also be highly time- and cost-effective comparatively to large-scale biomonitoring studies (Roig et al. 2009). They can be done with natural samples of sediments and waters, or with reproduced media that may or not mimic known concentrations of pesticides in the environment, with the latter further decreasing ecological relevance (Thain et al. 2008; Martins and Costa 2015). Barranger et al. (2014), for instance, studied the genotoxic effects of diuron in Crassostrea gigas and its inter-generational transmission in a fully laboratorial study that considered ecologically relevant concentrations of the herbicide in French river basins $\left(<1 \mu \mathrm{g} \mathrm{L}^{-1}\right)$. In another example, Stringer et al. (2014) deployed an estuarine copepod as model organism in bioassays to test the effects of sediments spiked with several toxicants, including the herbicide atrazine. Several authors highlighted, nonetheless, that laboratorial procedures may produce very distinct results from real-case scenarios, including the potential magnification of effects due, e.g., to favoured release of pesticides upon sediment disturbance, whereas natural sediments are likely in a steady-state (e.g. Costa et al. 2012a; Hommen et al. 2015). In general, by modulating the parameters of ex situ bioassays, from model organism to toxicant matrix, researchers are able to shift research from ecological relevance to more mechanistic endpoints, but always at some cost. In the particular case of ERA for estuarine environments, where challenges are exponentiated, "one-measure-fits-all" solutions are implausible. The choice of endpoints is thus of particular importance to circumvent the handicaps of the approach: multiple generalist biomarkers (such as histopathology or oxidative stress-related traits) and integration with sediment chemistry can be good immediate solutions.

In order to avoid the limitations of both conventional passive biomonitoring and pure ex situ bioassays, some researchers opt for an elegant, but still challenging, solution: testing in situ. This approach, also called "active biomonitoring" typically involves caging estuarine organisms at sites of interest (Costa et al. 2012a; Besse et al. 2012; Lacroix et al. 2015). This monitoring strategy provides a better control of biotic factors (e.g., interindividual genetic and physiological variability) by enabling selecting standard 
Fig. 1 Simplified overview of the Systems Biology principle applied to the ecotoxicology of pesticides. The exposome, which includes all factors that may affect the biota, including pesticides and other toxicants, acts upon every level of biological organisation. Ideally, the integration of multiple endpoints plus the characterisation of the exposome is integrated computationally into quantitative models used to derive pesticide-specific Adverse Outcome Pathways (AOPs) within a particular exposure scenario. The AOPs, which replace the classical single-endpoint "biomarker" concept, are then used to effectively predict risk

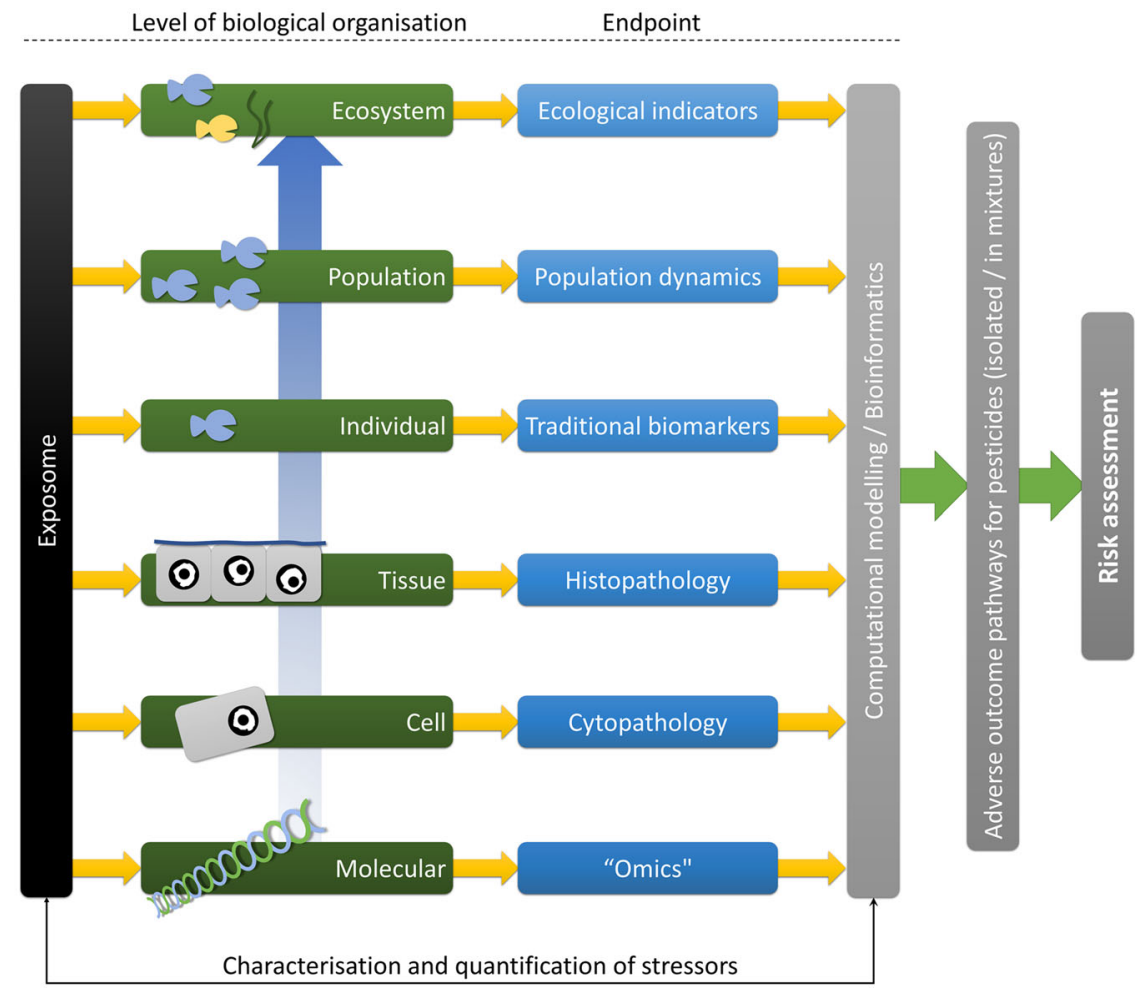

features like age, size and reproductive status following their collection from reference sites (then being usually termed "translocation" assays) or aquaculture facilities. It also permits controlling exposure time and facilitates intersite comparisons, as organisms come from the very same source. Lacroix et al. (2015) already suggested that estuarine organisms like mussels used in caging approaches are good bioindicators to assess pesticide contamination levels, since they are sensitive to these pollutants yet unbiased by previous adaptation processes. Nevertheless, some authors reported stress responses caused by transplanting (caging) procedures per se, especially with fish (Oikari 2006; Costa et al. 2012a, b).

\section{Novel approaches towards risk assessment}

As new pesticides come into market, the problem of contaminating complex ecosystems assumes a further additive character. Expectedly, the combination of "traditional" and "emerging" pollutants, plus the natural challenges of estuarine environments, dilutes toxicant-specific effects, compromising the traditional biomarker approach. To these constraints are added the obvious difficulties in detecting and quantifying the myriad of old and novel pesticides in the environment. For all these reasons, researchers are beginning to focus on methodologies that provide a broader insight on risk. These should be robust enough to handle complex toxicant mixtures and entangled environmental variables. For the purpose, the Systems Biology perspective initiated a revolution to address complex biological systems from a "top-down" perspective (i.e., from ecosystem to molecule). This approach, which ultimately aims at building predictive models for complex biological networks, is not new to ecotoxicologists (see the review by Garcia-Reyero and Perkins 2011). In fact, ecotoxicologists have been responsible for a number of novel applications and concepts related to the System Biology approach, including that of "adverse outcome pathways" (AOPs), which replaces the paradigmatic association between biomarker and toxicant by the more realistic toxicological pathway-exposome perspective that is need to address complex scenarios (Ankley et al. 2010).

Pushed by recent advances in high-content screening ("omics") and bioinformatics, toxicologists are now able to survey multiple molecular endpoints in single runs, therefore producing a pattern of alterations that can reveal disturbance of metabolic pathways, alternatively to classic biomarkers. These approaches, which include state-of-theart genomics, transcriptomics, proteomics, metabolomics and epigenomics, are a pillar of the Systems Biology paradigm, as outlined in Fig. 1 (see for instance Costa and Fadeel 2016). In this figure, we illustrate how this state-ofthe art approach to risk assessment can be enforced in a complex ecosystem. By integrating data collected from all levels of biological organization with comprehensive information on the "exposome", which includes (but should 
not excluded to) pollutant concentrations in the environment, computational models can reveal and predict novel AOPs. Not surprisingly, the rising field of bioinformatics takes a special role in System Biology. Within the context of ERA, proteomics and Next-Generation sequencing of whole-transcriptomes (RNAseq) are not so dependent of genomic annotation as, for instance, microarrays, which is a clear advantage to handle non-conventional model organisms (see Wang et al. 2009). For such reason, ecotoxicologists are beginning to venture into these methods to address exposure to pollutants, pesticides included, in ecologically relevant scenarios. Still, the application of omics in risk assessment of estuarine pollution is in its infancy and, in most, cases, circumscribed to laboratory work. The works by Montes-Nieto et al. (2010) and Costa et al. (2012b), with wild crab (Carcinus maenas) and caged sole (Solea senegalensis), respectively, used proteomics to address the problems of estuaries impacted my mixed pollutants, including metals, hydrocarbons and pesticides. Either work demonstrated the frailties of pinpointing specific substances to a range of effects in realistic scenarios but was successful to demonstrate metabolic imbalance resulting from exposure to mixed toxicants, even in low concentrations. The latter also highlighted that ex situ (laboratorial) bioassays enhanced the effects of sedimentbound hydrocarbons and organochlorine pesticides (DDT and metabolites), which caution is needed when selecting testing methods.

Rondon et al. (2016) analysed oyster (Crassostrea gigas) offspring after progenitors were exposed to realistic concentrations of the herbicide diuron during gametogenesis. The authors surveyed transcriptomic responses using RNAseq and disclosed disturbed pathways more related to basal metabolism and energy balance than to traditional toxicological endpoints, including classic oxidative stress biomarkers. In an earlier work, Connon et al. (2009) used a customised microarray to survey transcriptional responses in an endangered estuarine fish (Hypomesus transpacificus) exposed to the relatively novel insecticide esfenvalerate and, like in the previous paper, revealed that among the differentially expressed genes, those involved in detoxification processes were in the minority $(\approx 1 \%)$. Using a less conventional method, suppression subtractive hybridisation, which isolates differentially-transcribed PCR products between two experimental treatments, Tanguy et al. (2005) identified about 140 genes of interest in Crassostrea gigas exposed to a cocktail of herbicides after a 30-day exposure. As previous, the authors found that detoxification-related genes were a small part of the set. These findings are accordant with those from few works that addressed "omics" in situ. Hook et al. (2017), for instance, used RNASeq to survey whole-transcriptomes changes in the Australian catadromous fish Lates calcarifer collected from the wild. The worked aimed at addressing unspecified pesticide contamination in river catchments around the Great Reef area. Similarly to the studies mentioned above, the majority of dysregulated genes were related to basal metabolism, with evidence for xenobiotic metabolism, inferred from functional gene enrichment using the wellknown KEGG (Kyoto Encyclopedia of Genes and Genomes) tool for molecular pathways and bioinformatics. Altogether, these novel molecular approaches led to a rupture from the paradigmatic biomarker approach. Also, more than fulfilling the everlasting promise of finding new biomarkers, they can indicate perturbation of basal metabolism that are likely overlooked through traditional methods to assess individual health and population dynamics.

Among all "omics", metabolomics ( $\approx$ metabonomics) shows great promise, as it allows identification and quantification of the most downstream products of exposure to pollutants (refer to Yoshida et al. 2014, and references therein). However, the heavy expenditures of Nuclear Magnetic Resonance (NMR) and GC-MS methods render the approach little used in biomonitoring of estuaries and other complex environments. Still, Southam et al. (2011) used NMR-based metabolomics to study the effects of fenitrothion (a widely used organophosphate insecticide considered highly hazardous to aquatic life) on an estuarine teleost, the roach (Rutilus rutilus). This important work confirmed the suspicions that the pesticide affects androgen metabolism. A similar approach was used by Tuffnail et al. (2009) to address the toxicity of lindane and atrazine in mussels, revealing disruption of basal metabolism. Despite these ground-breaking examples, metabolomics has yet to be applied in realistic scenarios for the biomonitoring of pesticides in estuaries. Similarly, albeit the convincing evidence for epigenetic effects, such as DNA methylation, histone modifications and micro RNA (miRNA) action, from a wide range of pesticides (from DDTs to dieldrin and paraquat), studies have yet to leap the boundary between biomedical toxicology and ecotoxicology (Collotta et al. 2013).

In brief, methods associated with the Systems Biology approach (or "Systems Toxicology", in the case) can be applied to estuarine species to address the effects of pesticides, isolated, or more importantly, in realistic mixtures. These should involve multiple-omics, phenotypic anchoring of effects and responses and juxtaposition onto ecological effects, e.g., related to populational dynamics, to produce a more complete overview of the pesticide problem in these environments in order to ascertain cause-effect relationships and predict risk at the ecosystem level. This integrative perspective can circumvent the constraints of traditional biomarker-based biomonitoring by associating classes of toxicants with patterns of alterations at various levels of biological organisation and their underlying toxicological networks. 


\section{Concluding remarks}

Estuaries possess very unique features that undermine establishing conclusive cause-effect associations between pesticides and toxicity to biota. This begins with the fact that they are the ultimate fate and sink-of almost every class of natural or anthropogenic toxicant. Adding to the problem, ecotoxicologists face the ultimate challenge of keeping pace with novel pesticides that continuously replace banned compounds. Furthermore, in an estuary their effect is cumulative. Due to the very particular mode-ofaction of pesticides, which are designed against a wide range of organisms, from plants and fungi to molluscs and insects, they can affect every link in the complex estuarine food web (humans included). Altogether, the particular challenges of estuaries imply that Environmental Risk Assessment for pesticides in these ecosystems requires holistic, top-down approaches that cover all levels of biological organisation, and should be accompanied by accurate chemical determination of pesticides and their hazardous by-products. To meet this ambitious goal, being assisted by state-of-the-art high-content screening strategies and computational approaches, the Systems Biology approach is most likely to find its perfect battleground in estuaries and push risk assessment towards the nextgeneration of fully predictive models.

Funding The Portuguese Foundation for Science and Technology (FCT) is acknowledged for the funding for MARE through the strategic programme UID/MAR/04292/2013, and Unidade de Ciências Biomoleculares Aplicadas - UCIBIO which is financed by the national funds from FCT/MCTES (UID/Multi/04378/2013) and co-financed by the ERDF under the PT2020 Partnership Agreement (POCI-010145FEDER-007728) REQUIMTE. FCT is also acknowledged for the grants SFRH/BPD/109734/2015 to M.M. and IF/00265/2015 to P.M. C. The research project GreenTech (PTDC/MAR-BIO/0113/2014), also funded by FCT, is acknowledged as well for the funding of the fellowship to N.C.

\section{Compliance with ethical standards}

Conflict of interest The authors declare that they have no conflict of interest.

Ethical approval This article does not contain any studies with human participants or animals performed by any of the authors.

\section{References}

Ahrens L, Daneshvar A, Laua AE, Kreuger J (2015) Characterization of five passive sampling devices for monitoring of pesticides in water. J Chromatogr A 1405:1-11

Allan IJ, Vrana B, Greenwood R, Mills GA, Roig B, Gonzalez C (2006) A "toolbox" for biological and chemical monitoring requirements for the European Union's Water Framework Directive. Talanta 69:302-322
Anderson B, Phillips B, hunt J, Siegler K, Voorhees J, Smalling K, Hamilton M, Ranasinghe JA, Tjeederma R (2014) Impacts of pesticides in a Central California estuary. Environ Monit Assess 186:1801-1814

Ankley GT, Bennett RS, Erickson RJ, Hoff DJ, Hornung MW, Johnson RD, Mount DR, Nichols JW, Russom CL, Schmieder PK, Serrrano JA, Tietge JE, Villeneuve DL (2010) Adverse outcome pathways: a conceptual framework to support ecotoxicology research and risk assessment. Environ Toxicol Chem 29:730-741

Assoumani A, Lissalde S, Margoum C, Mazzella N, Coquery M (2013) In situ application of stir bar sorptive extraction as a passive sampling technique for the monitoring of agricultural pesticides in surface waters. Sci Total Environ 463-464:829-835

Barranger A, Akcha F, Rouxel J, Brizarda R, Maurouarda E, Palludb M, Menardb D, Tapiec N, Budzinski H, Burgeot T, Benabdelmouna A (2014) Study of genetic damage in the Japanese oyster induced by an environmentally-relevant exposure to diuron: evidence of vertical transmission of DNA damage Aquat Toxicol 146:93-104

Bereswill R, Golla B, Streloke M, Schulz R (2012) Entry and toxicity of organic pesticides and cooper in vineyard stream: erosion rills jeopardise the efficiency of riparian buffer strips. Agric Ecosyst Environ 146:81-92

Besse JP, Geffard O, Coquery M (2012) Relevance and applicability of active biomonitoring in continental waters under the Water Framework Directive. Trend Anal Chem 36:113-127

Bieroza MZ, Heathwaite AL (2015) Seasonal variation in phosphorus concentration-discharge hysteresis inferred from high-frequency in situ monitoring. J Hydrol 524:333-347

Borja A, Elliott M, Carstensen J, Heiskanen AS, van de Bund W (2010) Marine management-towards an integrated implementation of the European Marine Strategy Framework and the Water Framework Directives. Mar Pollut Bull 60:2175-2186

Brenner M, Broeg K, Frickenhaus S, Buck BH, Koehler A (2014) Multibiomarker approach using the blue mussel (Mytilus edulis L.) to assess the quality of marine environments: season and habitat-related impacts. Mar Environ Res 95:13-27

Brusick D, Aardema M, Kier L, Kirkland D, Williams G (2016) Genotoxicity Expert Panel review: weight of evidence evaluation of the genotoxicity of glyphosate, glyphosate-based formulations, and aminomethylphosphonic acid. Crit Rev Toxicol 46 (S1):56-74

Caeiro S, Vaz-Fernandes P, Martinho AP, Costa PM, Silva MJ, Lavinha J, Matias-Dias C, Machado A, Castanheira I, Costa MH (2017) Environmental risk assessment in a contaminated estuary: an integrated weight of evidence approach as a decision support tool. Ocean Coast Manag 143:51-62

Carson R (1962) Silent Spring.. Houghton Mifflin, Boston, MA, p 368

Carvalho PN, Rodrigues PNR, Basto MCP, Vasconcelos MTSD (2009) Organochlorine pesticides levels in Portuguese coastal areas. Chemosphere 75:595-60

Casida JE (2009) Pest toxicology: the primary mechanisms of pesticide action. Chem Res Toxicol 22:609-619

Ccanccapa A, Masiá A, Navarro-Ortega A, Picó Y, Barceló D (2016) Pesticides in the Ebro River basin: Occurrence and risk assessment. Environ Pollut 211:414-424

Cedergreen N (2014) Quantifying synergy: a systematic review of mixture toxicity studies within environmental toxicology. PLos ONE 5:e96580

Chapman PM, Wang F, Caeiro SS (2013) Assessing and managing sediment contamination in transitional waters. Environ Int 55:71-91

Chorney DS, Büyükpınar Ç, Turak F, Komesli OT, Bakırdere S (2017) Simultaneous determination of selected hormones, endocrine disruptor compounds, and pesticides in water medium at trace 
levels by GC-MS after dispersive liquid-liquid microextraction. Environ Monit Assess 189:277

Collotta M, Bertazzi PA, Bollati V (2013) Epigenetics and pesticides. Toxicology 307:35-41

Connon RE, Geist J, Pfeiff J, Loguinov AV, D'Abronzo L, Wintz H, Vulpe CD, Werner I (2009) Linking mechanistic and behavioral responses to sublethal esfenvalerate exposure in the endangered delta smelt; Hypomesus transpacificus (Fam. Osmeridae). BMC Genom 10:608

Cooper CM, Smith Jr. S, Moore MT (2003) Surface water, ground water and sediment quality in three oxbow lake watersheds in the Mississippi delta agricultural region: pesticides. Int $\mathrm{J}$ Ecol Environ Sci 29:1171-1184

Cooper J, Dobson H (2007) The benefits of pesticides to mankind and the environment. Crop Prot 26:1337-1348

Cortada C, Vidal L, Tejada S, Romo A, Canals A (2009) Determination of organochlorine pesticides in complex matrices by single-drop microextraction coupled to gas chromatography-mass spectrometry. Anal Chim Acta 638:29-35

Costa PM, Caeiro S, Vale C, DelValls TA, Costa MH (2012a) Can the integration of multiple biomarkers and sediment geochemistry aid solving the complexity of sediment risk assessment? A case study with a benthic fish. Environ Pollut 161:107-120

Costa PM, Chicano-Gálvez E, Caeiro S, Lobo J, Martins M, Ferreira AM, Caetano M, Vale C, Alhama-Carmona J, Lopez-Barea J, DellValls TÀ, Costa MH (2012b) Hepatic proteome changes in Solea senegalensis exposed to contaminated estuarine sediments: a laboratory and in situ survey Ecotoxicology 21:1194-1207

Costa PM, Carreira S, Costa MH, Caeiro S (2013) Development of histopathological indices in a commercial marine bivalve (Ruditapes decussatus) to determine environmental quality. Aquat Toxicol 126:442-454

Costa PM, Pinto M, Vicente AM, Gonçalves C, Rodrigo AP, Louro H, Costa MH, Caeiro S, Silva MJ (2014) An integrative assessment to determine the genotoxic hazard of estuarine sediments: combining cell and whole-organism responses. Front Genet 5:437

Costa PM, Fadeel B (2016) Emerging systems biology approaches in nanotoxicology: towards a mechanism-based understanding of nanomaterial hazard and risk. Toxicol Appl Pharmacol 299:101-111

Cruzeiro C, Amaral S, Rocha E, Rocha MJ (2017) Determination of 54 pesticides in waters of the Iberian Douro River estuary and risk assessment of environmentally relevant mixtures using theoretical approaches and Artemia salina and Daphnia magna bioassays. Ecotoxicol Environ Safe 145:126-134

Cruzeiro C, Rocha E, Pardal MA, Rocha MJ (2016a) Environmental assessment of pesticides in the Mondego River Estuary (Portugal). Mar Pollut Bull 103:240-246

Cruzeiro C, Rodrigues-Oliveira N, Velhote S, Pardal MA, Rocha E, Rocha MJ (2016b) Development and application of a QuEChERS-based extraction method for the analysis of 55 pesticides in the bivalve Scrobicularia plana by GC-MS/MS. Anal Bioannal Chem 408:3681-3698

Cuevas N, Zorita I, Costa PM, Larreta J, Franco J (2015) Histopathological baseline levels and confounding factors in common sole (Solea solea) for marine environmental risk assessment. Mar Environ Res 110:162-173

Domínguez I, González RR, Liébanas FJA, Vidal JLM, Frenich AG (2016) Automated and semi-automated extraction methods for GC-MS determination of pesticides in environmental samples. Trends Environ Anal Chem 12:1-12

Elibariki R, Maguta MM (2017) Status of pesticides pollution in Tanzania - a review. Chemosphere 178:154-164

Ferreira AM, Martins M, Vale C (2003) Influence of diffuse sources on levels and distribution of polychlorinated biphenyls in the Guadiana estuary (Portugal). Mar Chem 89:175-184
Garcia-Reyero N, Perkins EJ (2011) Systems biology: leading the revolution in ecotoxicology. Environ Toxicol Chem 30:265-273

Goldberg ED (1975) The mussel watch - a first step in global marine monitoring. Mar Pollut Bull 6:111

Greenstein DJ, Bay SM, Young DL, Asato S, Maruya KA, Lao W (2013) The use of sediment toxicity Identification evaluation methods to evaluate clean up targets in an urban estuary Integr Environ Assess Manag 10:260-268

Gwiazda R, Paull CK, Ussler W, Alexander CR (2015) Evidence of modern fine-grained sediment accumulation in the Monterey Fan from measurements of the pesticide DDT and its metabolites. Mar Geol 363:125-133

Hanke G, Mariani G, Comero S, Loos R, Bidoglio G, Polesello S, Valsecchi S, Rusconi M, Wollgast J, Castro-Jiménez J, Patrolecco L, Ademollo N (2012) Chemical-monitoring on-site exercises to harmonize analytical methods for priority substances in the European Union. Trends Anal Chem 36:25-35

Hering D, Borja A, Carstensen J, Carvalho L, Elliott M, Feld CK, Heiskanen AS, Johnson RK, Moe J, Pont D, Solheim AL, van de Bund W (2010) The European Water Framework Directive at the age of 10: a critical review of the achievements with recommendations for the future. Sci Total Environ 408:4007-4019

Hommen U, Forbes V, Grimm V, Preuss TG, Thorbek P, Ducrot V (2015) How to use mechanistic effect models in environmental risk assessment of pesticides: case studies and recommendations from the SETAC Workshop MODELINK. Integr Environ Assess Manag 12:21-31

Hook SE, Kroon FJ, Metcalfe S, Greenfield PA, Moncuquet P, McGrath A, Smith R, Warne MS, Turner RD, McKeown A, Westcott DA (2017) Global transcriptomic profiling in barramundi (Lates calcarifer) from rivers impacted by differing agricultural land uses. Environ Toxicol Chem 36:103-112

Izagirre U, Ramos R, Marigómez I (2008) Natural variability in size and membrane stability of lysosomes in mussel digestive cells: seasonal and tidal zonation. Mar Ecol Prog Ser 372:105-117

Juhel G, Bayen S, Goh C, Lee WK, Kelly BC (2017) Use of a suite of biomarkers to assess the effects of carbamazepine, bisphenol A, atrazine, and their mixtures on green mussels. Perna viridis Environ Toxicol 36:429-441

Kim Tiam S, Fauvelle V, Morin S, Mazzella N (2016) Improving toxicity assessment of pesticide mixtures: the use of polar passive sampling devices extracts in microalgae toxicity tests. Front Microbiol 7:1388

Lacroix C, Richard G, Seguineau C, Guyomarch J, Moraga D, Auffret M (2015) Active and passive biomonitoring suggest metabolic adaptation in blue mussels (Mytilus spp.) chronically exposed to a moderate contamination in Brest harbor (France). Aquat Toxicol 162:126-137

Lefrancq M, Jadas-Hécart A, La Jeunesse I, Landry D, Payraudeau S (2017) High frequency monitoring of pesticides in runoff water to improve understanding of their transport and environmental impacts. Sci Total Environ 587-588:75-86

Lehtonen KK, Sundelin B, Lang T, Strand J (2014) Development of tools for integrated monitoring and assessment of hazardous substances and their biological effects in the Baltic Sea. Ambio 43:69-81

Li J, Li F, Liu Q (2015) Sources, concentrations and risk factors of organochlorine pesticides in soil, water and sediment in the Yellow River estuary. Mar Pollut Bull 100:516-522

Lord H, Pawliszyn J (2000) Evolution of solid-phase microextraction technology. J Chromatogr A 885:153-193

Lorenz S, Rasmussen JJ, Süß A, Kalettka T, Golla B, Horney P, Stähler M, Hommel B, Schäfer RB (2016) Specifics and challenges of assessing exposure and effects of pesticides in small water bodies. Hydrobiologia 793:213-224 
Martins M, Costa PM (2015) The comet assay in environmental risk assessment of marine pollutants: applications, assets and handicaps of surveying genotoxicity in non-model organisms. Mutagenesis 30:89-106

Martins M, Costa PM, Raimundo J, Vale C, Ferreira AM, Costa MH (2012) Impact of remobilized contaminants in Mytilus edulis during dredging operations in a harbour area: Bioaccumulation and biomarker responses. Ecotoxicol Environ Safe 85:96-103

Matthews GA (2015) Pesticides: Health, Safety and the Environment, Second Edition. Wiley, Chichester, UK, p 296

Meffe R, de Bustamante I (2014) Emerging organic contaminants in surface water and groundwater: a first overview of the situation in Italy. Sci Total Environ 481:280-295

Montes Nieto R, García-Barrera T, Gómez-Ariza J-L, López-Barea J (2010) Environmental monitoring of Domingo Rubio stream (Huelva Estuary, SW Spain) by combining conventional biomarkers and proteomic analysis in Carcinus maenas. Environ Pollut 158:401-408

Montuori P, Aurino S, Garzonio F, Sarnacchiaro P, Nardone A, Triassi M (2016) Distribution, sources and ecological risk assessment of polycyclic aromatic hydrocarbons in water and sediments from Tiber River and estuary, Italy. Sci Total Environ 566-567: 1254-1267

Mrema EJ, Rubino FM, Brambilla G, Moretto A, Tsatsakis AM, Colosio C (2013) Persistent organochlorinated pesticides and mechanisms of their toxicity. Toxicology 307:74-88

Muir D, Sverko E (2006) Analytical methods for PCBs and organochlorine pesticides in environmental monitoring and surveillance: a critical appraisal. Anal Bioanal Chem 386:769-789

Oikari A (2006) Caging techniques for field exposures of fish to chemical contaminants. Aquat Toxicol 78:370-381

Perron MM, Burgess RM, Suuberg EM, Cantwell MG, Pennell KG (2013) Performance of passive samplers for monitoring estuarine water column concentrations: 1 . contaminants of concern. Environ Toxicol Chem 32:2182-2189

Pesce S, Morin S, Lissalde S, Montuelle B, Mazzella N (2011) Combining polar organic chemical integrative samplers (POCIS) with toxicity testing to evaluate pesticide mixture effects on natural phototrophic biofilms. Environ Pollut 159:735-741

Poletta GL, Larriera A, Kleinsorge E, Mudry MD (2009) Genotoxicity of the herbicide formulation Roundup ${ }^{\circledR}$ (glyphosate) in broadsnouted caiman (Caiman latirostris) evidenced by the Comet assay and the Micronucleus test. Mutat Res 672:95-102

Regoli F, Gorbi S, Fattorini D, Tedesco S, Notti A, Machella N, Bocchetti R, Benedetti M, Piva F (2006) Use of the land snail Helix aspersa as sentinel organism for monitoring ecotoxicologic effects of urban pollution: an integrated approach. Environ Health Perspect 114:63-69

Reichenberger S, Bach M, Skitschak A, Frede HG (2007) Mitigation strategies to reduce pesticide inputs into ground and surface water and their effectiveness; a review. Sci Total Environ 384:1-35

Ricciardi F, Matozzo V, Binelli A, Marin MG (2010) Biomarker responses and contamination levels in crabs (Carcinus aestuarii) from the Lagoon of Venice: an integrated approach in biomonitoring estuarine environments. Water Res 44:1725-1736

Rodrigo AP, Costa PM, Costa MH, Caeiro S (2013) Integration of sediment contamination with multi-biomarker responses in a novel potential bioindicator (Sepia officinalis) for risk assessment in impacted estuaries. Ecotoxicology 22:1538-1554

Roig B, Allan I, Mills GA, Guigues N, Greenwood R, Gonzalez C (2009) Existing and new methods for chemical and ecological status monitoring under the WFD. In: Gonzalez C, Greenwood R,
Quevauviller P (Eds.) Rapid chemical and biological techniques for water monitoring.. Wiley, Chichester, UK, p 39-50

Rondon R, Akcha F, Alonso P, Menard D, Rouxel J, Montagnani C, Mitta G, Cosseau C, Grunau C (2016) Transcriptional changes in Crassostrea gigas oyster spat following a parental exposure to the herbicide diuron. Aquat Toxicol 175:47-55

Routti H, van Bavel B, Letcher RJ, Arukwe A, Chu S, Gabrielsen GW (2009) Concentrations, patterns and metabolites of organochlorine pesticides in relation to xenobiotic phase I and II enzyme activities in ringed seals (Phoca hispida) from Svalbard and the Baltic Sea. Environ Pollut 157:2428-2434

Schäfer RB, Caquet T, Siimes K, Mueller R, Lagadic L, Liess M (2007) Effects of pesticides on community structure and ecosystem functions in agricultural streams of three biogeographical regions in Europe. Sci Total Environ 382:272-285

Scheurell M, Franke S, Hühnerfuss H (2007) Effect-directed analysis: a powerful tool for the surveillance of aquatic systems. Int $\mathrm{J}$ Environ Anal Chem 87:401-413

Smalling KL, Reilly TJ, Sandstrom MW, Kuivila KM (2013a) Occurrence and persistence of fungicides in bed sediments and suspended solids from three targeted use areas in the United States. Sci Total Environ 447:179-185

Smalling KL, Kuivila KM, Orlando JL, Phillips BM, anderson BS, Siegler K, Hunta JW, Hamilton M (2013b) Environmental fate of fungicides and other current-use pesticides in a central California estuary. Mar Pollut Bull 73:144-153

Southam AD, Lange A, Hines A, Hill EM, Katsu Y, Iguchi T, Tyler CR, Viant MR (2011) Metabolomics reveals target and off-target toxicities of a model organophosphate pesticide to roach (Rutilus rutilus): implications for biomonitoring. Environ Sci Technol 45:3759-3767

Stringer TJ, Glover CN, Keesing V, Northcott GL, Gaw S, Tremblay LA (2014) Development of acute and chronic sediment bioassays with the harpacticoid copepod Quinquelaophonte sp. Ecotoxicol Environ Saf 99:82-91

Tanguy A, Boutet I, Laroche J, Moraga D (2005) Molecular identification and expression study of differentially regulated genes in the Pacific oyster Crassostrea gigas in response to pesticide exposure. FEBS J 272:390-403

Thain JE, Vethaak AD, Hylland K (2008) Contaminants in marine ecosystems: developing an integrated indicator framework using biological-effect techniques. ICES J Mar Sci 65:1508-1514

Tuffnail W, Mills GA, Cary P, Greenwood R (2009) An environmental ${ }^{1} \mathrm{H}$ NMR metabolomic study of the exposure of the marine mussel Mytilus edulis to atrazine, lindane, hypoxia and starvation. Environ Sci Pollut Res 5:33-43

USEPA (2007) Sediment Toxicity IdentificationEvaluation (TIE). Phases I, II and III. Guidance document. EPA/600/R-07/080

van den Berg (2009) Global status of DDT and its alternatives for use in vector control to prevent disease. Environ Health Perspect 117:1656-1663

van der Oost R, Beyer J, Vermeulen NP (2003) Fish bioaccumulation and biomarkers in environmental risk assessment: a review. Environ Toxicol Pharmacol 13:57-149

Vrana B, Allan IJ, Greenwood R, Mills GA, Dominiak E, Svensson K, Knutsson J, Morrison G (2005) Passive sampling techniques for monitoring pollutants in water. Trends Anal Chem 24:845-868

Wang Z, Gerstein M, Snyder M (2009) RNA-Seq: a revolutionary tool for transcriptomics. Nat Rev Genet 10:57-63

Yoshida S, Date Y, Akama M, Kikuchi J (2014) Comparative metabolomic and ionomic approach for abundant fishes in estuarine environments of Japan. Sci Rep 4:7005 